\title{
A Comparison of the Postoperative Analgesic Efficacy of Two Different Doses of Caudal Clonidine as Adjunct to Caudal Bupivacaine in Infraumbilical Surgeries in Younger Children
}

\author{
Subinay Chhaule ${ }^{1}$, Manotosh Sutradhar ${ }^{2}$, Puja Trigunait ${ }^{3}$, Tanweer Qamar ${ }^{4}$, Sayani Lahari ${ }^{5}$, \\ Rina Das ${ }^{6}$, Indranil Thakur ${ }^{7}$, Asutosh Ghosh ${ }^{8}$
}

\begin{abstract}
${ }^{1}$ Department of Critical Care Medicine, IPGME \& R, Kolkata, West Bengal, India. ${ }^{2}$ Department of Critical Care Medicine, IPGME \& R, Kolkata, West Bengal, India. ${ }^{3}$ Department of Critical Care Medicine, IPGME \& R, Kolkata, West Bengal, India. ${ }^{4}$ Department of Critical Care Medicine, IPGME \& R, Kolkata, West Bengal, India. ${ }^{5}$ Department of Community Medicine, COM \& JNM Hospital, Kalyani, West Bengal, India. ${ }^{6}$ Department of Forensic Medicine, R. G. Kar Medical College, Kolkata, West Bengal, India. ${ }^{7}$ Department of Critical Care Medicine, IPGME \& R, Kolkata, West Bengal, India. ${ }^{8}$ Department of Critical Care Medicine, IPGME \& R, Kolkata, West Bengal, India.
\end{abstract}

\section{ABSTRACT}

\section{BACKGROUND}

Managing peri operative pain in smaller children is challenging but beneficial. Caudal epidural block with local anaesthetic and adjuvant in proper dose can significantly prolong the duration of analgesia while avoiding dose related side effects of both the drugs. We selected clonidine as adjuvant to bupivacaine in caudal blocks for perioperative pain management in 80 children during infra umbilical surgeries performed under general anaesthesia.

\section{METHODS}

The children were randomly allocated into two groups, Group A ( $\mathrm{n}=40)$ and Group B $(\mathrm{n}=40)$. Group A received caudal bupivacaine $(0.125 \%) 0.75 \mathrm{~mL} / \mathrm{Kg}$ plus clonidine 1 $\mu \mathrm{g} / \mathrm{Kg}$ in $1 \mathrm{~mL}$ normal saline and Group B received caudal bupivacaine $(0.125 \%) 0.75$ $\mathrm{mL} / \mathrm{Kg}$ plus clonidine $0.5 \mu \mathrm{g} / \mathrm{Kg}$ in $1 \mathrm{~mL}$ normal saline, after inhalational anaesthesia. Heart rate, blood pressure, respiratory rate, oxygen saturation, sedation score, Bromage score and pain score were monitored and recorded peri-operatively. Time to first rescue analgesic at pain score of 12 , total number of rescue analgesic doses required, and side effects were also recorded. Data was analysed using appropriate statistical tests.

\section{RESULTS}

Group B patients had significantly higher heart rates, systolic and diastolic blood pressures, respiratory rates and pain scores compared to Group A patients at 50 mins post operatively. The requirement of rescue analgesics in Group B was earlier and higher than Group A. Group A patients remained haemodynamically stable and pain free for longer period. There was no significant difference in side effects between the groups.

\section{CONCLUSIONS}

Addition of $1 \mu \mathrm{g} / \mathrm{Kg}$ clonidine to caudal epidural bupivacaine improves the quality and prolongs the duration of postoperative analgesia compared to addition of 0.5 $\mu \mathrm{g} / \mathrm{Kg}$ clonidine without causing significant side effects.

\section{KEY WORDS}

Caudal Epidural, Local Anaesthetic Adjuvant, Clonidine, Infraumbilical Surgery

\author{
Corresponding Author: \\ Dr. Sayani Lahari, \\ Mohan Tower, Flat No. 2E, 28-B, \\ Chaul Patty Road, \\ Beliaghata, Kolkata-700010, \\ West Bengal, India. \\ E-mail:drsayanilahari@gmail.com
}

DOI: $10.14260 / \mathrm{jemds} / 2020 / 512$

How to Cite This Article:

Chhaule S, Sutradhar M, Trigunait P, et al. A comparison of the postoperative analgesic efficacy of two different doses of caudal clonidine as adjunct to caudal bupivacaine in infraumbilical surgeries in younger children. J Evolution Med Dent Sci 2020;9(33):2361-2366, $10.14260 /$ jemds/2020/512

Submission 05-04-2020,

Peer Review 08-07-2020,

Acceptance 15-07-2020,

Published 17-08-2020.

Copyright (c) 2020 JEMDS. This is an open access article distributed under Creative Commons Attribution License [Attribution 4.0 International (CC BY 4.0)] 


\section{BACKGROUND}

Post-operative increase in sympathetic tone and endogenous catecholamine release produces pain leading to agitation, anxiety, increase in heart rate, respiratory rate, and systemic arterial pressures in children. So, attenuation of postoperative pain may decrease perioperative morbidity and mortality. ${ }^{1}$ Perioperative pain management to alleviate neuroendocrine stress response caused by surgery in paediatric patients is still an enigma to the anaesthesiologists for the challenge of balancing adequate pain relief and acceptable adverse effects. Though deficiency of routine pain assessment interferes with effective pain management, ${ }^{2}$ evidence-based practice and innovative approaches have made effective perioperative analgesia an important component of modern paediatric anaesthesiology. For analgesia, among different routes for administering analgesics, caudal epidural is the oldest and still commonly used technique in children. Stable haemodynamics and prevention of neurotransmitter release after caudal block post operatively facilitate surgical wound repair, reduces parents' anxiety, hospitalization time and finance. Central neuraxial blocks do not affect left ventricular function and are virtually free of significant hemodynamic effects, at least up to 8 years. But with growth, caudal technique becomes less suitable and difficult children older than 6 to 7 years. Fluid preloading and vasopressors are usually unnecessary. ${ }^{3}$ Caudal blocks are used to supplement and reduce the requirement of general anaesthetic agents and provide good postoperative analgesia.

The disadvantage of single-shot caudal anaesthesia is the shorter duration of postoperative analgesia. Many agents have been studied to find out an additive that would prolong the duration of analgesia by single shot technique. Clonidine, an alpha 2 agonist, can be safely administered neuraxially and is being used as an adjunct to local anaesthetics to prolong the duration of analgesia. It almost doubles the duration of nerve blockade without affecting haemodynamics, decreases peak plasma L A concentration and produces light sedation for 1 to 3 hours postoperatively. Addition of clonidine often makes placement of continuous epidural catheter unnecessary. Clonidine produces analgesia by interacting with alpha 2 adrenergic receptors on superficial laminae of spinal cord and brainstem nuclei for pain, producing analgesia at peripheral, spinal and brain stem site. Sedation, produced by clonidine, reduces hypnotic requirement and is often desirable. ${ }^{4}$ Clonidine is mostly metabolized by liver $(50 \%)$ and excreted by kidney.

Clonidine is beneficial in children when added to local anaesthetics neuraxially. Addition of clonidine significantly prolongs the duration of surgical analgesia produced by local anaesthetics during caudal block in children. ${ }^{6}$ But even in recommended dose of $1-1.5 \mu \mathrm{g} / \mathrm{Kg}$ it causes side effects including hypotension, bradycardia and sedation. The recommended strength of bupivacaine in paediatric epidural block is 0.125 to $0.25 \%$.

In this study we comparatively observed the efficacy and side effects of two doses of clonidine $(1 \mu \mathrm{g} / \mathrm{Kg}$ and $0.5 \mu \mathrm{g} / \mathrm{Kg})$ added to caudal bupivacaine $(0.125 \%) 0.75 \mathrm{~mL} / \mathrm{Kg}$ to the two groups of children undergoing infraumbilical surgeries under inhalational anaesthesia.

\section{METHODS}

We carried out this randomized, parallel group, doubleblinded study after approval of the institutional ethical committee. Taking time to first rescue analgesic dose as the primary outcome measure it was estimated that a number of 40 patients per group (total 80 ) would be required to detect a 60 minutes difference in between groups with a power of $85 \%$ and a 5\% probability of type I error. Written informed consents were taken from parents of the 80 children of either sex, aged 2 to 7 years, ASA physical status I \& II, admitted in the department of Surgery and Orthopaedics for different infraumbilical surgeries between March 2017 to February 2019. Parental refusal, major sacral malformations, meningitis, intracranial hypertension, bleeding disorders, hypersensitivity to local anaesthetics and clonidine, hepatic and renal disorders were excluded. Patients were divided into two groups $\mathrm{A}$ and $\mathrm{B}$, in equal numbers of 40 as per computerized randomization table.

\section{Procedure}

After collecting the baseline data namely body weight, heart Rate (HR),respiratory rate (RR),blood pressure (SBP, DBP), temperature, oxygen saturation $\left(\mathrm{SpO}_{2}\right)$; children were premedicated with syrup midazolam $0.5 \mathrm{mg} / \mathrm{Kg}$ administered 45 mins before the scheduled time of surgery. 5 Following induction of Standard light volatile anaesthesia with halothane, I t was maintained using spontaneous mask ventilation. Thereafter caudal blocks were performed for every patient aseptically. Group A patients were administered bupivacaine $(0.125 \%) 0.75 \mathrm{~mL} / \mathrm{Kg}$ and clonidine $1 \mu \mathrm{g} / \mathrm{Kg}$. Group B patients were administered bupivacaine $(0.125 \%)$ $0.75 \mathrm{~mL} / \mathrm{Kg}$ and clonidine $0.5 \mu \mathrm{g} / \mathrm{Kg}$. Total drug volume injected was $1 \mathrm{~mL} / \mathrm{Kg}$ (maximum $20 \mathrm{~mL}$ ) in both groups using normal saline as dilutant. ${ }^{6}$ Monitoring of vital signs was continued throughout the procedure. Before starting surgery, 15 minutes after caudal block procedure, sensory testing was done by gentle skin pinching. During surgery the patients received lactated ringers' solution $6 \mathrm{~mL} / \mathrm{Kg} /$ hour and postoperatively $5 \%$ dextrose in half strength normal saline 4 $\mathrm{mL} / \mathrm{Kg} /$ hour. No intra operative sedatives or opioids were administered. At the end of surgery volatiles were discontinued and the patients were sent to postoperative care unit.

Caudal block completion time, surgery initiation time, surgery completion time, heart rate, systolic blood pressure, diastolic blood pressure, oxygen saturation were noted every 10 minutes intra operatively. Hypotension (decrease in MAP $>30 \%$ of baseline) was treated with rapid IV fluid and or mephentermine. Bradycardia (decrease in heart rate $>30 \%$ of the baseline) was treated with injection atropine $0.02 \mathrm{mg} / \mathrm{Kg}$ intravenously.

\section{RESULTS}

\section{Post-Operative Parameters Noted}

a) Duration of Analgesia, Documented by Broadman Observational Pain Score (OPS). ${ }^{7}$ 


\begin{tabular}{|cccc|}
\hline Behavioural Objectives & None & Moderate & Severe \\
Crying & 1 & 2 & 3 \\
Facial expression & 1 & 2 & 3 \\
Position of legs & 1 & 2 & 3 \\
Position of torso & 1 & 2 & 3 \\
Motor restlessness & 1 & 2 & 3 \\
\hline Chart 1. Broadman Observational Pain Score Chart \\
\hline
\end{tabular}

Patients were given rescue analgesia, paracetamol 10 $\mathrm{mg} / \mathrm{Kg}$ orally when ops was $>12$.

b) Sedation, as assessed by a 4-point sedation scoring as below

- 1-asleep, not arousable by verbal command.

- 2-asleep, arousable by verbal command.

- 3-drowsy.

- 4-alert.

c) Duration of motor block, by modified Bromage scale noting the time for regaining of full motor power.

d) Cardiovascular status, by recording heart rate (HR), blood pressures.

e) Side effects, nausea, vomiting, respiratory depression, urinary retention.
These parameters were noted hourly for initial 6 hours and $2^{\text {nd }}$ hourly from $6^{\text {th }}$ hour after completion of surgery up to $12^{\text {th }}$ hour.

\section{Statistical Analysis}

Data were summarised by routine descriptive statistics namely mean and standard deviation for normally distributed numerical variables and median for skewed numerical variables. Numerical variables were compared between groups by Student's independent samples t-test or MannWhitney U test, as appropriate. Fisher exact test was applied for within group comparison of categorical variables. $p<0.05$ was taken as cut off for statistical significance.

\begin{tabular}{|ccccccccc|}
\hline Group & $\mathbf{n}$ & $\mathbf{M}$ & $\mathbf{F}$ & Mean S.D. $\begin{array}{c}\text { Mean } \\
\text { Weight (Kg) }\end{array}$ & S.D. & $\begin{array}{c}\text { Mean Weight } \\
\text { (Kg) }\end{array}$ \\
A & 40 & $\begin{array}{c}33 \\
(82.5 \%)\end{array}$ & $\begin{array}{c}7 \\
(17.5 \%)\end{array}$ & 4.65 & 1.61 & 18.30 & 4.34 & $\mathbf{1 8 . 3 0}$ \\
B & $\begin{array}{c}32 \\
40\end{array}$ & $\begin{array}{c}8 \\
(80 \%)\end{array}$ & $\mathbf{4 . 6 0}$ & 1.59 & 17.60 & 4.34 & $\mathbf{1 7 . 6 0}$ \\
\hline \multicolumn{6}{|c|}{ Table 1. Sex, Age (Years) Profile and Body Weight of the Patients } \\
\hline
\end{tabular}
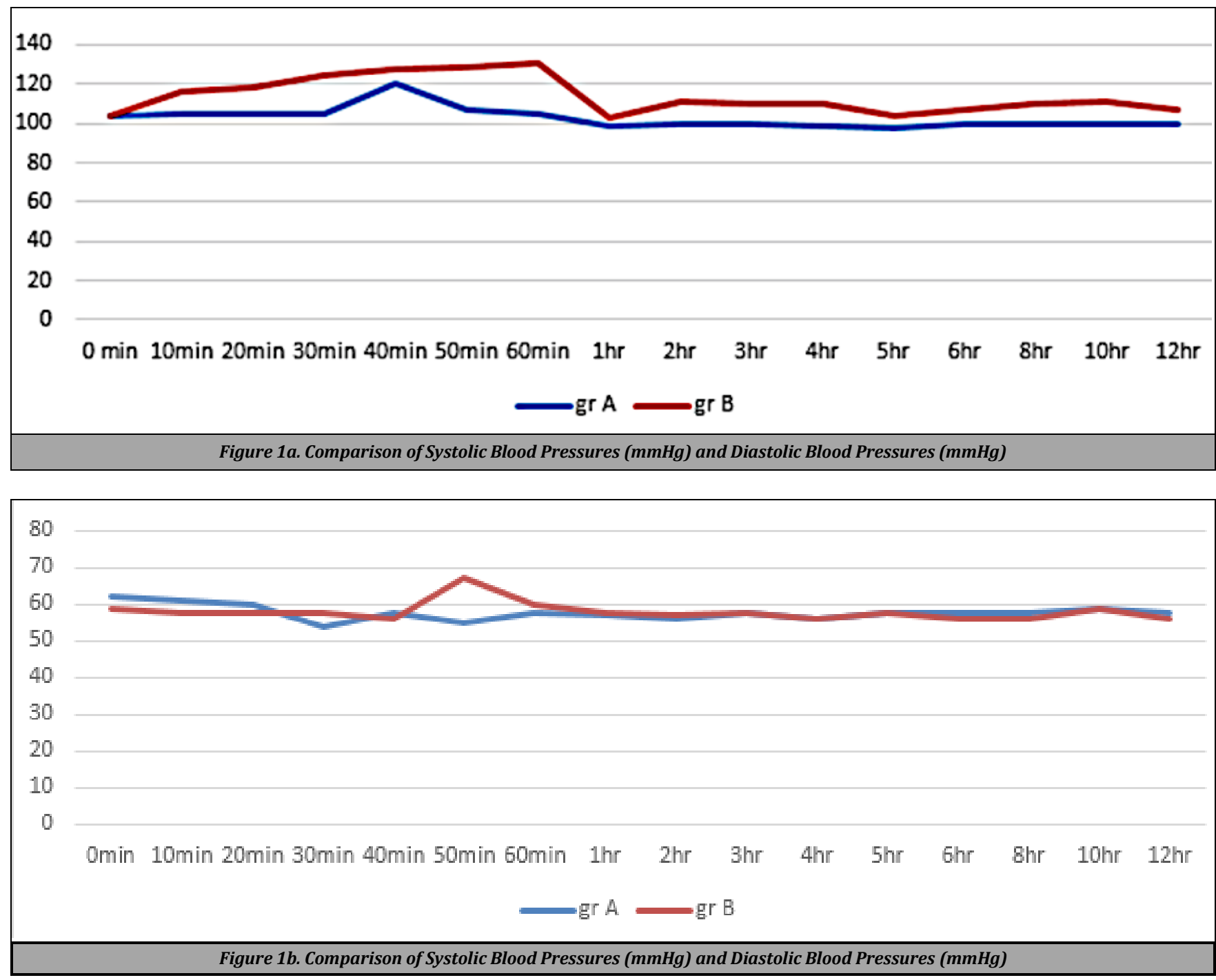

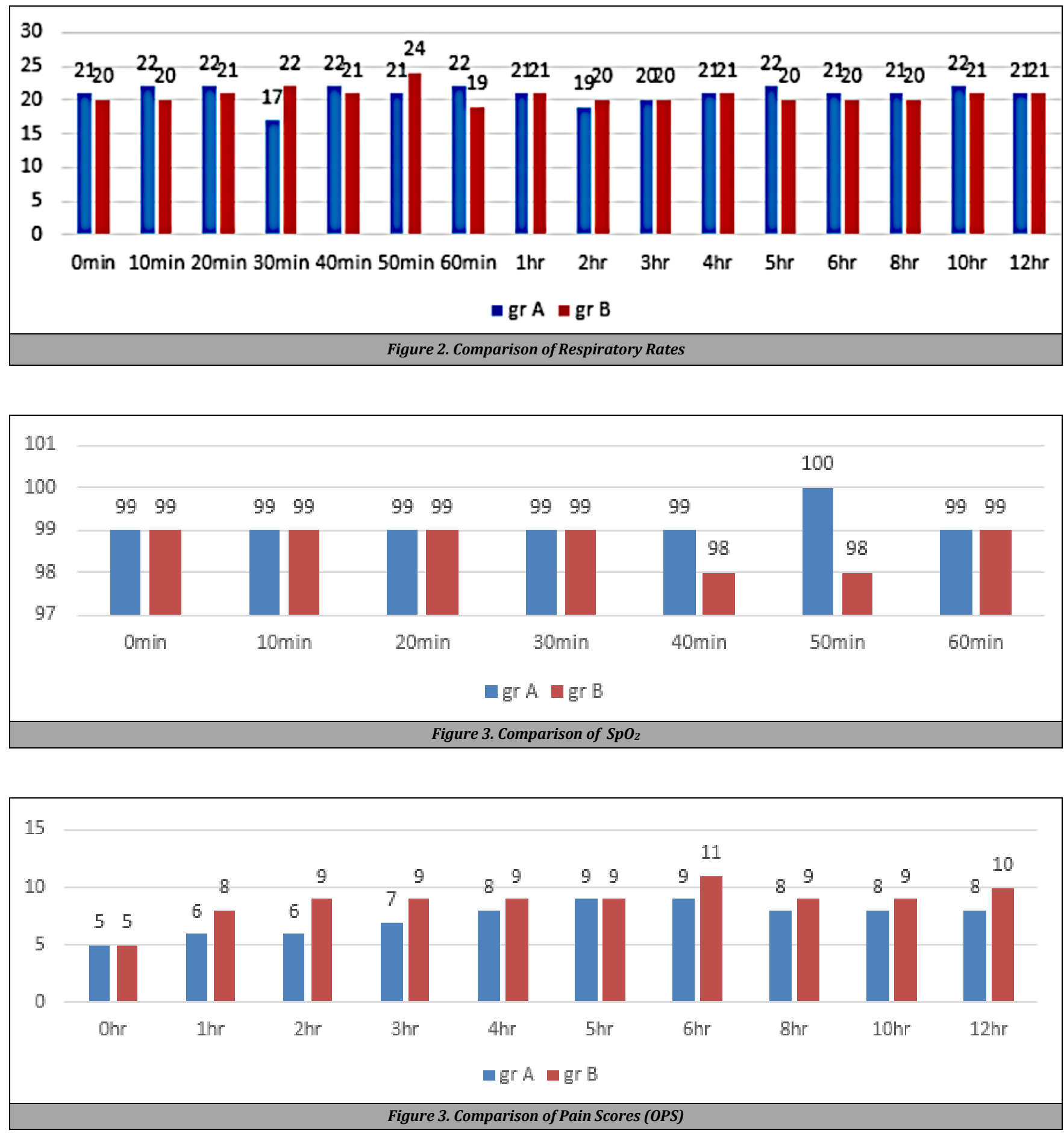

\begin{tabular}{|c|c|c|c|c|c|c|}
\hline Group & N & Mean & S.D. & 1 Dose & 2 Doses & 3 Doses \\
\hline A & 40 & $\mathbf{3 7 0 . 7 5}$ & 45.39 & $\mathbf{1 6}$ & $\mathbf{2 0}$ & $\mathbf{4}$ \\
\hline B & 40 & 190.25 & 57.40 & 2 & 19 & 19 \\
\hline Table 2. Comparison of Time to First Rescue Analgesic Dose (Minutes) \\
and Comparison of Total Number of Rescue Analgesic Doses \\
\hline
\end{tabular}

\section{DISCUSSION}

Both the groups were comparable with respect to demographic characteristics (Table 1). The different surgeries performed and the duration of surgeries didn't show significant difference between them. Analysing the distribution of mean HR between the two groups we found the median HR at 50 mins was significantly higher in Group B than in Group A (Mann Whitney U Test, p<0.001) at 50 mins and within Group B at 0 hours; 10,20, 30,40,60 minutes; 1,2,3,4,5,6,8,10 and 12 hours. In Group A patients the median HR at 12 hours was significantly lower than the median HR at 0 hours.

Figure 1 show the comparative SBP and DBP between the two groups. The median SBP\& DBP at 50 mins was significantly higher in Group B than Group A. The comparative changes in SBP \& DBP in both Groups at different time points were found to be highly significant. In Group B patients the median SBP\& DBP at 50 mins was significantly higher when compared to the median SBP\& DBP at 0 hours; $10,20,30,40,60$ minutes; $1,2,3,4,5,6,8,10$ and 12 hours. In Group A patients the median SBP \& DBP at 12 hours were not significantly lower than the median SBP\& DBP at 0 hours. Figure 2 shows 
significant changes in comparative RR between the study groups sat various time points. In Group B, the median RR at 50 mins was significantly higher when compared to the median RR at 0 hours; 10, 20, 30, 40, 60 minutes; $1,2,3,4,5,6,8,10$ and 12 hours than within group and Group A patients. In Group A patients the median RR at 30 mins was significantly lower than the median RR at 0 hours. Figure 2 also shows the comparison of SPO2 values between the groups at various time points and they were not significantly different $(\mathrm{p}>0.05)$.

The data from the study indicate that there was a significant increase in heart rate, systemic blood pressures and respiratory rates in Group Bat 50 minutes peri operatively compared to Group A, indicating inadequate pain relief in Group Band the addition of $1 \mu \mathrm{g} / \mathrm{Kg}$ clonidine must have prolonged the duration of analgesia in Group A. Thus, postoperative analgesia provided by caudal bupivacaine plus $0.5 \mu \mathrm{g} / \mathrm{Kg}$ clonidine was unable to maintain a stable hemodynamic status beyond 1 hour postoperatively.

In group A patients there was no significant increase in HR, SBP, DBP and RR throughout the 12 hours postoperative period. There was a significant decrease in all the three parameters at 30 minutes compared to the preoperative values. However, there was no clinically significant bradycardia, hypotension or respiratory depression. Thus, the decrease in heart rate, systemic blood pressure and respiratory rates may be attributed to the diminished sympathetic tone due to better postoperative analgesia achieved by the bupivacaine- $1 \mu \mathrm{g} / \mathrm{Kg}$ clonidine combination. These findings are corroborative with the clinical studies by several investigators. $8,9,10,11$

Figure 3 shows the comparison of OP Sat various times between the two groups. The median pain score sat 0 hour and 1 hour postoperatively were similar. The median OPS at 6 hours was significantly higher in Group B compared to Group A ( $p<0.001$, Group B:11, Group A: 9). So, in Group B, caudal 0.5 $\mu \mathrm{g} / \mathrm{Kg}$ clonidine failed to provide adequate postoperative analgesia beyond 1 hour.

Comparative sedation scores between the groups showed, the median values were not significantly different from 5 hours up to 12 hours post operatively ( $\mathrm{P}>0.05$ ). But scores were comparatively lower in group $A$ than group Bat $0,1,2,3$ and 4 hours. Comparison of the median B rom age scores between the two groups showed no significant statistical difference $(\mathrm{p}>0.05)$.

Table 2 shows the comparative mean duration of pain relief deduced from the time to first rescue analgesic between the two groups. The median value was higher (372.5 minutes; Mean \pm SD: $370.75 \pm 45.39$ ) in Group A than Group B (185 minutes; Mean \pm SD: $190.25 \pm 57.40$ ) showing significant difference $(\mathrm{p}<0.001)$.

Table 2 also shows the comparative number of rescue analgesic doses required between the groups. There was no significant difference between the groups with respect to the patients needing two doses (Group A: $B=20: 19$ ). But there was significant difference $(p<0.001)$ in the number of patients needing one dose (Group A: $B=16: 2$ ) and three doses (Group $A: B=4: 19$ ). Thus the patients in Group A required less recue analgesic than Group Bin the 12 hours period.

So, it can be concluded that bupivacaine and $1 \mu \mathrm{g} / \mathrm{Kg}$ clonidine combination provided superior analgesia compared to bupivacaine and $0.5 \mu \mathrm{g} / \mathrm{Kg}$ clonidine. Upadhyay K.K. et al,
2005 similarly observed the superior analgesia by caudal bupivacaine clonidine combination. W. Klimscha et al, 1998 showed lesser consumption of rescue analgesic when clonidine was used in the dose of $2 \mu \mathrm{g} / \mathrm{Kg}$ compared to $1 \mu \mathrm{g} / \mathrm{Kg}$ body weight.

The comparative side effects between the groups were not significant. The incidence of vomiting (Group B: $12.5 \%$ Group A: $17.5 \%$ ), urinary retention (Group A: $2.5 \%$, Group B: $5 \%$ ) and nausea (Group A: 7.5\%, Group B: 5\%) were not clinically significant. None of the patients in either group suffered from respiratory depression or hypotension. The in significant incidence of nausea and vomiting in the study by J. J. Lee et al, 1994, corroborates with our study. Other previous studies by Jamali S et al, 1994, W. Climscha et al, 1998, Upadhyay K.K. et al, 2005, also showed no significant increase in the incidence of side effects.

So, our observations were that, addition of $1 \mu \mathrm{g} / \mathrm{Kg}$ clonidine to bupivacaine administered caudally prolongs the duration of postoperative analgesia of bupivacaine up to $370.75 \pm 45.39$ minutes compared to $190.25 \pm 57.40$ minutes with $0.5 \mu \mathrm{g} / \mathrm{Kg}$ clonidine. The bupivacaine $-1 \mu \mathrm{g} / \mathrm{Kg}$ clonidine group had lower heart rates, systemic blood pressures, respiratory rates and pain scores for more than 6 hours postoperatively than the bupivacaine- $0.5 \mu \mathrm{g} / \mathrm{Kg}$ clonidine group.

\section{CONCLUSIONS}

Addition of $1 \mu \mathrm{g} / \mathrm{Kg}$ clonidine to caudal epidural bupivacaine effectively prolongs the duration and improves the quality of post-operative analgesic effect of bupivacaine compared to addition of $0.5 \mu \mathrm{g} / \mathrm{Kg}$ clonidine, and $1 \mu \mathrm{g} / \mathrm{Kg}$ dose may be the least clinically significant and effective additive dosage of clonidine as caudal epidural adjuvant for prolongation of analgesia.

Financial or Other Competing Interests: None.

\section{REFERENCES}

[1] Liu S. Carpenter RL, Neal JM. Epidural anesthesia and analgesia. Their role in post-operative outcome. Anesthesiology 1995;82(6):1474-506.

[2] American Academy of Pediatrics and American Pain Society. The assessment and management of acute pain in infants, children and adolescents. Pediatrics 2001;108(3):793-7.

[3] Dalen BJ. Regional anaesthesia in children. In: Miller RD, ed. Miller's anesthesia. $6^{\text {th }}$ edn. Philadelphia: Churchill Livingstone Elsevier 2010:1719-32.

[4] Butterworth JF, Mackey DC, Wasnick JD. Paediatric anesthesia. In: Morgan \& Mikhail's clinical anesthesiology. $4^{\text {th }}$ edn. New York: McGraw-Hill 2008: p. 928.

[5] Cummings EA, Reid GJ, Finley GA, et al. Prevalence and source of pain in Pediatric inpatients. Pain 1996;68(1):25-31. 
[6] Anand KJ, Hickey PR. Halothane-morphine compared with high-dose sufentanil for anaesthesia and postoperative analgesia in neonatal cardiac surgery. $\mathrm{N}$ Engl J Med 1992;326(1):1-9.

[7] Broadman LM, Rice LJ, Hannallah RS. Testing the validity of an objective pain scale fob infants and children. Anesthesiology 1988;69:A770.

[8] Jamali S, Monin S, Begon C, et al. Clonidine inpaediatric caudal anesthesia. Anesth Analg 1994;78:663-6.

[9] Lee JJ, Rubin AP. Comparison of bupivacaine-clonidine mixture with plain bupivacaine for caudal analgesia in children. Br J Anaesth 1994;72(3):258-62.
[10] Klimscha W, Chiari A, Sauberer AM, et al. The efficacy and safety of clonidine-bupivacaine combination in caudal blockade for paediatric hernia repair. Anesth Analg 1998;86(1):54-61.

[11] Upadhyay KK, Prabhakar T, Handa R, et al. Study of the efficacy and safety of clonidine as an adjunct to bupivacaine for caudal analgesia in children. Indian J Anaesth 2005;49(3):199-201. 